\title{
Non-invasive Screening of Autoimmune Atrophic Gastritis in Asymptomatic Subjects by Serological Biomarker Test $\left(\right.$ GastroPanel $^{\circledR}$ )
}

\author{
NATALIA BAKULINA ${ }^{1}$, SERGEY TIKHONOV ${ }^{1}$, VLADIMIR MALKOV ${ }^{2}$, SERGEY VOROBYEV $^{3}$, \\ ILYA BELYAKOV ${ }^{3}$, NATALIYA PESHKOVA ${ }^{4}$, ELENA BELKO ${ }^{4}$ and KARI SYRJÄNEN ${ }^{5,6}$ \\ ${ }^{1}$ Department of Internal Medicine, Clinical Pharmacology and Nephrology of North-Western \\ State Medical University, I.I. Mechnikov, St. Petersburg, Russian Federation; \\ ${ }^{2}$ St. Petersburg State University Hospital, St. Petersburg, Russian Federation; \\ ${ }^{3}$ Department of Pathology, National Center of Clinical Morphological Diagnostics, \\ St. Petersburg, Russian Federation; \\ ${ }^{4}$ INVITRO SPb LLC, St. Petersburg, Russian Federation; \\ ${ }^{5}$ Molecular Oncology Research Center, Barretos Cancer Hospital, Barretos, Brazil; \\ ${ }^{6}$ SMW Consultants, Ltd., Kaarina, Finland
}

\begin{abstract}
Background/Aim: To estimate the prevalence of autoimmune atrophic gastritis (AAG) in the Russian Federation, a systematic screening of asymptomatic healthy adults by non-invasive biomarker testing was conducted. The aim was i) To test the validity of non-invasive serological screening for $A A G$; ii) to establish the prevalence of $A A G$ among asymptomatic adults. Patients and Methods: Altogether, 1,283 asymptomatic, healthy adults (mean age: 38 years) were screened by GastroPanel ${ }^{\circledR}$ test. Those with a biomarker profile indicating $A G(n=46)$ were invited for further examinations; 21 consented to gastroscopy with biopsies classified using the Updated Sydney System and Operative Link to Gastric Atrophy. Blood tests included parietal cell, intrinsic factor and thyroid peroxidase antibodies, and analysis of vitamin B12 and iron. Results: Gastroscopy and biopsies confirmed $A G$ in 20 of the individuals. Parietal cell, intrinsic factor and thyroid
\end{abstract}

Correspondence: Professor Kari Syrjänen, MD, Ph.D., FIAC, SMW Consultants Ltd., Kylliäisentie 9, FI-21620 Kuusisto, Finland. Tel: +358405566810, e-mail: kasyrja@netti.fi

Key Words: Atrophic gastritis, autoimmune, serological biomarker panel, GastroPanel ${ }^{\circledR}$, non-invasive test, updated Sydney System, Helicobacter pylori, pepsinogen, gastrin-17, Hp IgG antibody, parietal cell antibody, intrinsic factor antibody.

This article is an open access article distributed under the terms an conditions of the Creative Commons Attribution (CC BY-NC-ND) 4.0 international license (https://creativecommons.org/licenses/by-nc-nd/4.0). peroxidase antibodies were present in five, one and eight individuals, respectively. AAG-associated co-morbidities (iron deficiency and pernicious anemia) were diagnosed in 10 out of 21. The final diagnosis of AAG was made in 15 out of 1,283 subjects (1.2\%), of whom four were Helicobacter pylori-positive. When corrected for verification bias (nonattendees in the confirmatory tests; $n=25)$, the adjusted prevalence of $A A G$ was $2.6 \%$ (33/1,283). Conclusion: $A A G$ prevalence of $2.6 \%$ is among the highest reported using noninvasive tests. GastroPanel ${ }^{\circledR}$ is an optimal screening tool, providing the first link in the diagnostic protocol leading to the final diagnosis of this condition. The role of Helicobacter pylori as a trigger of AAG cannot be ruled out.

Autoimmune atrophic gastritis (AAG) is characterized by atrophy of the gastric corpus and fundus, and the presence of circulating autoantibodies to parietal cells (PCA) and to their secretory product, intrinsic factor (IFA) (1-5). In the general population, there is an age-related increase in the prevalence of PCA, from $2.5 \%$ in the third decade to $12 \%$ in the eighth decade $(6,7)$. The prevalence is markedly higher in those affected by other autoimmune disorders, frequently accompanied by pernicious anemia (PA) (8-10). Thus, in patients with type 1 diabetes mellitus (DM1), PCAs are found in $10-15 \%$ of children and in $15-25 \%$ of adults (1113). The respective prevalence of AAG and PA in the general population are $2 \%$ and $0.15-1 \%$ (14-16), compared with 5$10 \%$ and $2.6-4 \%$, respectively, among patients with DM1 $(15,17-19)$. In patients with autoimmune thyroid disease (AITD), AAG is concomitantly detected in up to one-third of patients (20-24). 
AAG is associated with significant co-morbidities, including iron deficiency anemia found in $20-40 \%$ of patients $(25,26)$, and PA is diagnosed in up to $15-25 \%(3,4$, 27). The progression to $P A$ in patients with $A A G$ is likely to span 20-30 years (28). Finally, gastric carcinoid tumors are observed in 4-9\% of the patients with AAG/PA, which is 13 times more frequent than in controls (29-32). Patients with AAG/PA also have a 3- to 6-fold increased risk of gastric cancer, ranging from $0.9-9 \%(29,30,32-35)$.

In most cases, like AG associated with Helicobacter pylori infection, AAG is asymptomatic and diagnosed as incidental finding among patients examined for other conditions, such as iron-deficiency anemia, PA or other autoimmune conditions $(2,36)$. The diagnosis of AAG is confirmed by gastroscopy and biopsies, demonstrating mucosal atrophy in the corpus but sparing of the antrum $(1-5,8,9,37)$. Being an invasive diagnostic technique, however, gastroscopy cannot be considered as a tool for systematic, populationbased screening for asymptomatic AAG, non-invasive diagnostic methods, i.e., serology, are used instead. The most sensitive serum biomarker for AAG is PCA, detected by enzyme-linked immunosorbent assay (ELISA), although detection of IFA is more specific than PCA (1-4, 8-10). The sensitivity of IFA is very low, but rises in parallel with disease progression $(1,3,4)$. PCA, targeted against gastric $\mathrm{H}^{+} / \mathrm{K}^{+}$ATPase, are detected in $60-85 \%$ and IFA in $30-50 \%$ of patients with AAG $(17,38)$.

An interesting proposal was made by Antico et al., who suggested a combination of testing for PCA and IFA with anti-H. pylori and serum gastrin as a 'serological biopsy' for diagnosis of AAG, shown to be useful in classification of gastritis (39). The latest development in the field of serological biopsy is a panel combining serum pepsinogen I (PGI) and II (PGII), gastrin-17 and H. pylori IgG antibodies using ELISA, the GastroPanel ${ }^{\circledR}$ test (Biohit Oyj, Helsinki, Finland), proposed as a first-line diagnostic test for dyspeptic symptoms, as well as for screening of asymptomatic individuals for AG/AAG (40-42). Since its introduction in the early 2000s (43), GastroPanel ${ }^{\circledR}$ has been extensively tested in different clinical and screening settings worldwide (44-48), and its high accuracy in diagnosis of AG was confirmed in two recent meta-analyses $(49,50)$.

The present study is the first in which GastroPanel ${ }^{\circledR}$ test was used for systematic screening for AAG in a cohort of asymptomatic healthy volunteers, followed by confirmation of AAG by gastroscopic biopsies and AAG-specific serological tests (PCA and IFA).

\section{Patients and Methods}

Study subjects. The study subjects in this screening trial represent asymptomatic, healthy volunteers who consented to participate in the study as a part of the preventive health care program arranged by their employer (AO Werteks, St. Petersburg, Russian Federation). All employees of the company were asked to participate in the study by providing written consent. All those who were asymptomatic and did not report any upper abdominal symptoms were considered eligible. The study protocol followed the Declaration of Helsinki, and the whole trial was approved (April 22, 2020) by the Institutional Review Board (Astarta Ltd. Co, St. Petersburg, Russian Federation), fulfilling the rigorous ethical principles applied to clinical studies in the country (no. 04/2020). Altogether, 1,283 study subjects were enrolled and had completed the first round (GastroPanel ${ }^{\circledR}$ screening) by the end of summer 2021. Their mean age ( \pm standard deviation) was 38 years $( \pm 11.2$ years) (range $=19-79$ years). Of the 1,283 participants, 758 $(59 \%)$ were women and $525(41 \%)$ were men.

Study design. This study was a systematic screening trial targeted to all the employees of a single company (AO Werteks) in St. Petersburg (Russian Federation). All study subjects were healthy adults with no dyspeptic or other gastric symptoms, who volunteered to be screened by GastroPanel ${ }^{\circledR}$ test to reveal asymptomatic AAG.

In the first study round (screening), all participants donated a blood sample for analysis by the new-generation GastroPanel ${ }^{\circledR}$ test. This test categorizes the biomarker profiles into five diagnostic endpoints: i) Healthy stomach, ii) superficial H. pylori-related gastritis, iii) AG of the antrum (AGA); iv) AG of the corpus (AGC), and v) AG of the antrum and corpus, pan-gastritis (AGP) $(42,43-48,51)$.

In the second round, all those who tested positive for AG in GastroPanel ${ }^{\circledR}$ (profiles iii-v) were contacted personally by the study monitors, asking for their consent to participate in the second phase of the study, which included gastroscopy and biopsies, as well as blood sampling for measurement of the following: Transferrin, iron, PCA, IFA, vitamin B12 (total + active), and TPO (antibodies to thyroid peroxidase).

Figure 1 shows the study flowchart. Of the 1,283 subjects examined by GastroPanel ${ }^{\circledR}$ test, 46 had a test result indicating AGC or AGP. Of the 46 individuals who were invited to participate in the second round, 25 either did not receive an invitation (i.e., were not reached) or refused to participate. This left a total of 21 subjects who completed both study rounds and were analyzed in detail to confirm or exclude AAG.

The GastroPanel ${ }^{\circledR}$ test. The GastroPanel ${ }^{\circledR}$ used in this study is the original test version containing four biomarkers (Pepsinogen I, Pepsinogen II, Gastrin-17, and H. pylori IgG ELISA), processed using automated ELISA technique and biomarker-specified processing conditions $(43,46-48)$.

Sample processing for GastroPanel ${ }^{\circledR}$ test. Test results are interpreted by the GastroSoft ${ }^{\circledR}$ application (Biohit Oyj, necessitating completion of the GastroPane ${ }^{\circledR}$ request form with pertinent clinical information $(43,46-48,51)$. A minimum of $2 \mathrm{ml}$ EDTA plasma from a fasting blood sample was taken into an EDTA tube, frozen instantly $\left(-70^{\circ} \mathrm{C}\right)$, as instructed by the manufacturer $(43,46-48,51)$.

GastroPanel ${ }^{\circledR}$ testing. All plasma samples were delivered to the laboratory (LabStori Laboratories, St. Petersburg, Russia) for analysis with the conventional GastroPane $l^{\circledR}$ test version following the instructions detailed elsewhere $(43,46-48,51)$.

GastroPanel ${ }^{\circledR}$ results were interpreted by the GastroSoft ${ }^{\circledR}$ application. The GastroPanel ${ }^{\circledR}$ test was designed for use with the Updated Sydney System (USS) classification of gastritis (52), both 


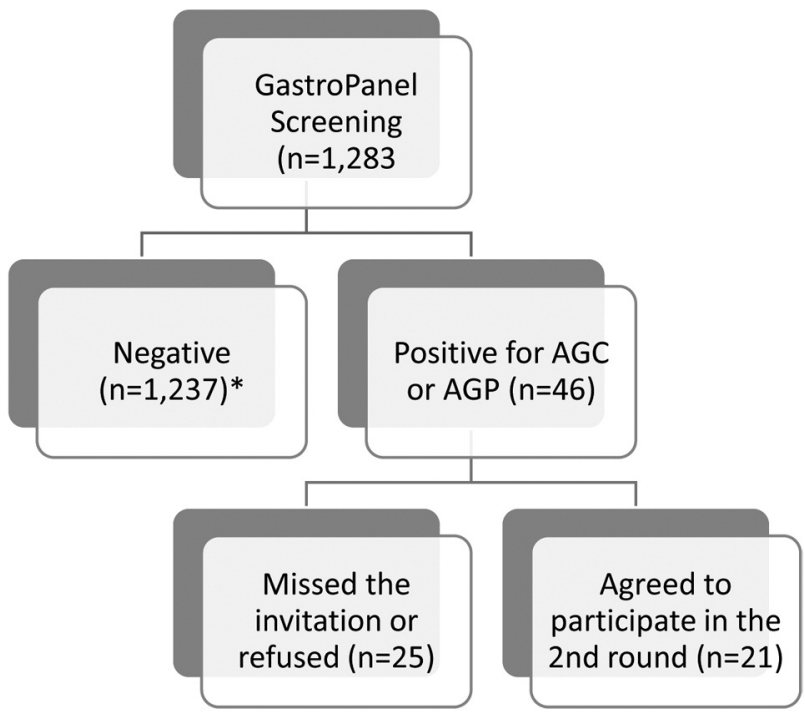

Figure 1. Flowchart of the study subjects in the two rounds of the study. AGC: Atrophic gastritis of the corpus; AGP: atrophic gastritis in both the antrum and corpus. *Normal, or Helicobacter pylori infection with no atrophy.

using the same diagnostic categories: a) Normal mucosa, b) $H$. pylori-related gastritis with no atrophy, c) AGA, d) AGC, and e) AGP $(40,41,44-52)$

Gastroscopy and biopsies. In this study, a total of 21 individuals who consented to participate in the second study round underwent gastroscopy and biopsies at the Department of Internal Medicine (St. Petersburg State University Hospital). Macroscopic endoscopy findings were classified using the adopted practice of the clinic, the endoscopist being blinded to the GastroPanel ${ }^{\circledR}$ results. Endoscopic findings were classified into one of the following categories: i) Normal; ii) inflammation; iii) suspected atrophy; iv) definite atrophy; v) atrophy and intestinal metaplasia; and vi) other abnormality.

Gastroscopic biopsies followed the protocol of the USS, targeting both the antrum and corpus (52). All biopsies were examined by expert pathologists at the Department of Pathology (National Center of Clinical Morphological Diagnostics, St. Petersburg, Russia). The diagnoses were classified using the USS classification for gastritis (52) as AGA, AGC or AGP, and all lesions were classified as mild, moderate or severe in degree. In addition, the pathologists also classified all biopsies using the OLGA staging (53).

All biopsies were stained with Giemsa stain for specific demonstration of $H$. pylori, quantified using a semi-quantitative 4-tier grading: $0=$ absent; $1=H$. pylor $i$ present in small quantities; $2=H$. pylor $i$ present in moderate quantities; and $3=H$. pylori present in abundance $(47,52)$. In some statistical testing, a 3-tier grading was also used, where grades 2 and 3 were combined. Immunohistochemical staining for chromogranin was performed to assess the level of enterochromaffin-like cell (ECL) hyperplasia in the atrophic corpus. Conventional immunohistochemistry procedures were followed and chromogranin expression was graded as normal or intense in the biopsies from gastric corpus.
Laboratory tests for $A A G$. In the second study round, blood was sampled for analysis of the markers that are indirect or direct indicators of AAG. These include the following: ferritin, iron, PCA, IFA, vitamin B12 (total + active), and antibodies to thyroid peroxidase (TPA). Ferritin and iron were analyzed using conventional laboratory tests. Active vitamin B12 was measured using the test for active vitamin B12 (Biohit Oyj) as instructed (54). Also, the total B-12 vitamin was measured using Architect i2000sr (Abbott Laboratories, Abbott Park, IL, USA; reference: 187-883 $\mathrm{pg} / \mathrm{ml}$ ). The levels of PCA were measured by ImmuGlo ${ }^{\text {TM }}$ COVI III Rat Liver/Kidney/Stomach IFA kit (IMMCO Diagnostics, Amherst, NY, USA) (reference titer $<1: 40$ ). The levels of IFA were measured by anti-intrinsic factor (Orgentec Diagnostika $\mathrm{GmbH}$, Mainz, Germany) (reference $<6 \mathrm{EIU} / \mathrm{ml}$ ). TPA were tested using Architect Anti-TPO Reagent (Abbott Laboratories; reference $<5.6 \mathrm{EIU} / \mathrm{ml}$ ).

Statistical analyses. All statistical analyses were performed using the SPSS 27.0.1.0 for Windows (IBM, Armonk, NY, USA). The descriptive statistics were performed according to routine procedures. All tests were two-sided and interpreted as significant at the level of $\mathrm{p}<0.05$.

\section{Results}

GastroPanel ${ }^{\circledR}$ test was performed for all 1,283 individual who consented to participate in the screening trial (Table I). The most frequent test result was $H$. pylori-associated gastritis with no atrophy, detected in 736/1,283 (57.4\%). GastroPanel ${ }^{\circledR}$ test was normal in $38.7 \%(n=496)$ of the cases. The disease of interest, i.e., AG was distinguished by its biomarker profile in 51 study subjects (3.97\%). Because AAG only affects the gastric corpus leaving the antrum intact (1-5), the five patients with the GastroPanel ${ }^{\circledR}$ profile of AGA were not invited for further examinations.

Of the 46 invited to undergo second round testing, 21 finally consented to participate. The GastroPanel ${ }^{\circledR}$ profiles of these patients are illustrated in Table II. The 20 cases with the AGC biomarker profile, the PGI level was low and the PGI/PGII ratio very low, with concomitant extremely high gastrin-17, and $H$. pylori-positive test with mean values above the cut-off (30.0 EIU). As expected, the gastrin-17 level was very low in the one case classified as AGP.

In the second round of the study, all consenting participants $(n=21)$ attended the clinic and underwent gastroscopic examination with multiple biopsies, as well as a series of laboratory tests for diagnosis of AAG (Table III). Women clearly predominated in this group (at 15:6, i.e., 2.5:1). The mean age of this group was 12 years older than the whole screened cohort. Gastroscopic examination confirmed AG in all 21 patients, accompanied by signs of intestinal metaplasia in seven of them. In 17/21 patients, OLGA stage was far advanced (stage 2 or 3 ). Histological examination of the biopsies failed to find any atrophy in one case, while AGA was found in one instead of predicted AGC. ECL hyperplasia was present in all but four cases, classified as moderate to 
Table I. Results of the GastroPanel ${ }^{\circledR}$ test in the screened cohort of 1,283 asymptomatic subjects.

\begin{tabular}{|c|c|c|c|c|c|c|}
\hline Biomarker profile & No. of cases & PGI, $\mu \mathrm{g} / 1$ & PGII, $\mu \mathrm{g} / 1$ & PGI:PGII & Gastrin-17, pmol/1 & HpA, EIU \\
\hline Normal & 496 & $86.8 \pm 292.5$ & $6.0 \pm 3.2$ & $15.5 \pm 5.2$ & $3.5 \pm 6.6$ & $10.6 \pm 8.0$ \\
\hline Hp infection & 736 & $100.4 \pm 36.4$ & $13.6 \pm 9.5$ & $9.0 \pm 3.7$ & $7.7 \pm 10.0$ & $94.4 \pm 51.6$ \\
\hline AGA & 5 & $59.5 \pm 22.5$ & $6.2 \pm 2.6$ & $10.8 \pm 6.4$ & $0.5 \pm 0.4$ & $103.0 \pm 26.2$ \\
\hline AGC & 43 & $25.8 \pm 28.9$ & $13.3 \pm 10.7$ & $1.7 \pm 1.0$ & $34.6 \pm 11.3$ & $63.4 \pm 43.2$ \\
\hline AGP & 3 & $26.1 \pm 2.7$ & $6.8 \pm 4.0$ & $5.7 \pm 5.0$ & $0.9 \pm 0.3$ & $87.7 \pm 43.1$ \\
\hline
\end{tabular}

AGA: Atrophic gastritis of the antrum; AGC: atrophic gastritis of the corpus; AGP: atrophic gastritis of both antrum and corpus; G-17: gastrin-17; Hp: Helicobacter pylori; HpA: Helicobacter pylori IgG antibody by enzyme-linked immunosorbent assay; PGI: pepsinogen I; PGII: pepsinogen II. Data are the means \pm standard deviation.

Table II. Results of the GastroPanel ${ }^{\circledR}$ test in the 21 study subjects who completed the second round of testing.

\begin{tabular}{lclllcc}
\hline Biomarker profile & No. of cases & PGI, $\mu \mathrm{g} / 1$ & PGII, $\mu \mathrm{g} / 1$ & PGI:PGII & Gastrin-17, pmol/1 & HpA, EIU \\
\hline AGC & 20 & $11.4 \pm 9.4$ & $7.4 \pm 3.9$ & $1.3 \pm 0.9$ & $31.9 \pm 14.0$ & $48.1 \pm 46.8$ \\
AGP & 1 & 26.5 & 2.3 & 11.5 & 1.2 & 38.7 \\
\hline
\end{tabular}

AGA: Atrophic gastritis of the antrum; AGC: atrophic gastritis of the corpus; AGP: atrophic gastritis of both antrum and corpus; G-17: gastrin-17; HpA: Helicobacter pylori IgG antibody by enzyme-linked immunosorbent assay; PGI: pepsinogen I; PGII: pepsinogen II. Data are the means \pm standard deviation.

severe in 13. Not unexpectedly, chromogranin expression in the ECL cells was almost invariably intense (19/21 cases).

The laboratory tests designed for finding evidence of AAG disclosed iron deficiency in four patients (Table III). Vitamin B12 deficiency was revealed in 6/21 (28.6\%) cases. Similarly, PCA or IFA were detected in six $(28.6 \%)$ of the patients, whereas eight $(38 \%)$ patients had high titers of TPA.

Table IV summarizes the case profiles of all 21 secondround study subjects, listing the results of the clinical and laboratory tests used to reach the final diagnosis. For each of these 21 subjects, at least one of the tests was abnormal, in addition to biopsy-confirmed AGC/AGP. There was one patient (no. 5; a female aged 46 years), however, in whom the biopsy failed to confirm AG and all the AAG tests were normal. However, the clinical finding in gastroscopy was definite $\mathrm{AG}$, and the GastroPanel ${ }^{\circledR}$ biomarker profile was typical for AGC. Based on the laboratory and clinical findings listed in Table IV, the final diagnosis of the 21 cases were as follows: a) normal stomach in one; b) AG with no evidence on autoimmune origin in five; c) AAG in 15 .

\section{Discussion}

The prevalence of AAG is dependent on the technique used for the diagnosis, i.e., whether based on detection of vitamin B12 deficiency, IFA or PCA (1, 3, 6-9, 14-16). According to the global data, the prevalence of AAG in the general population varies between $0.1 \%$ and $1-2 \%$ (1-9). In studies based on esophagogastroduodenoscopy, the prevalence of AAG is higher, from $0.3 \%$ to $2.7 \%(1,3,30,32)$. AAG is significantly more common, however, among particular groups of people, particularly those with other autoimmune disorders (11-24). Accordingly, 36-44\% of patients with AAG have AITD (20-24), while DM1 increases the risk of AAG by up to 3-5-fold as compared with the general population $(15,17,19)$. There is at least a $2: 1$ female predominance among patients with $\operatorname{AAG}(1,3)$.

Studies on AAG prevalence in the Russian Federation are scant $(55,56)$. In two recent surveys based on serological biomarker screening for $H$. pylori infection and AG in the Russian Federation using GastroPanel ${ }^{\circledR}$ (45, 47), the prevalence of $H$. pylori infection in a population with mean age of $50+$ years was high $(64-76 \%)$, and AG (any topography) was diagnosed in $10.8 \%$ (99 out of the 918 subjects screened) (45). Both surveys used the GastroPanel ${ }^{\circledR}$ test, which does not include a specific biomarker for AAG (40-42, 51), precluding an accurate assessment of the proportion of AAG. However, indirect evidence can be obtained by using the assumption that all AGC and AGP cases that are $H$. pylori-negative are potentially an autoimmune type of AG. Using this approach in the recent survey data (45), where out of 78 AGC/AGP cases, 28 proved to be $H$. pylori-negative, results in an AAG prevalence estimate of $3.05 \%$ (28/918) (45). Undoubtedly, this estimate might be inaccurate because of the known fact that Helicobacter frequently disappears during the protracted 
clinical course of AGC/AGP, and is no longer detectable in severe AG $(42-49,57)$. As discussed later, however, this estimate seems to match fairly with the results of the present study (2.6\% AAG prevalence), where specific tests were used for diagnosis of AAG, and when the AAG prevalence $(15 / 1,283)$ is being corrected for the non-attendees $(33 / 1,283)$ in the second study round.

The present study is the first ever conducted screening of asymptomatic healthy adults for AAG by a non-invasive serological test in the Russian Federation $(45,47,55,56)$. In this study, the serological biomarker test (GastroPanel ${ }^{\circledR}$ ), which accurately detects AG and its topography (AGA, AGC, AGP) as well as $H$. pylori infection as the causative agent, was supplemented with other diagnostic tests that are used for diagnosis of AAG-associated co-morbidity (iron deficiency and vitamin $\mathrm{B} 12$ deficiency), detecting autoantibodies to gastric $\mathrm{H}^{+} / \mathrm{K}^{+}$ATPase in parietal cells (PCA) and their secretory product, IF, as well as measuring TPA as an indicator of AITD (which frequently accompanies AAG) (20-24).

The GastroPanel ${ }^{\circledR}$ test was performed for all 1,283 subjects who consented to participate in the screening trial (Table I). As anticipated in an asymptomatic cohort of subject aged $38 \pm 11.2$ years, the expected rate of gastric pathologies was rather low. Consistent with published GastroPanel ${ }^{\circledR}$ screening studies in the Russian Federation, $H$. pylori infection was a frequent finding, detected in $57.4 \%$ of the subjects $(45,47)$. In our cohort, the prevalence of $H$. pylori infection was slightly lower than that (64-76\%) in the two previous studies. This is explained by the fact that the mean age of the subjects in the present cohort was 12 years younger than that of the two previous studies (around 50 years), indicating that in this country, the prevalence of $H$. pylori infection also seems to be declining in a birth cohortrelated manner as shown elsewhere (58).

GastroPanel ${ }^{\circledR}$ biomarker profiles were consistent with AG in 51 cases, i.e., in $3.97 \%$ of the screened individuals (Table I). Because of the fact that AAG (targeting the PCs in the corpus) does not affect the antrum (1-5), the five patients with the GastroPanel ${ }^{\circledR}$ profile of AGA were not of interest in this study. Given that AGC has a dual etiology: namely chronic $H$. pylori infection, and an autoimmune mechanism, one could argue that the correct prevalence of AAG could be simply reached by assigning all AGC and AGP cases that are H. pylori-negative in the GastroPanel ${ }^{\circledR}$ test to the AAG group. This would be in line with the original thinking when the GastroPanel ${ }^{\circledR}$ test was designed, and indeed, re-iterated in many studies and reviews addressing this biomarker test (40-51, 57). In the light of the accumulated new evidence, however, that would be an oversimplification of the issue, and lead to underestimates of the AAG prevalence, as discussed below.

The reasons for this discordance are two-fold: i) in chronic AGC, Helicobacter frequently disappears during the
Table III. Clinical and laboratory findings of the 21 participants who completed the study.

\begin{tabular}{llc}
\hline Finding & Subgroup & Value \\
\hline Gender, n (\%) & Women & $15(71.4)$ \\
Age, years & Men & $6(28.6)$ \\
& Mean \pm SD & $50.8 \pm 13.6$ \\
Gastroscopy, n (\%) & Range & $25-76$ \\
& Atrophic gastritis & $14(66.7)$ \\
OLGA Stage, n (\%) & AG and IM & $7(33.3)$ \\
& 0 & $1(4.7)$ \\
& 1 & $3(14.3)$ \\
USS Classification, n (\%) & 2 & $7(33.3)$ \\
& 3 & $10(47.7)$ \\
& Normal & $1(4.7)$ \\
ECL hyperplasia, n (\%) & AGA & $1(4.7)$ \\
& AGC & $18(85.7)$ \\
& AGP & $1(4.7)$ \\
& None & $4(19.0)$ \\
& Mild & $4(19.0)$ \\
Chromogranin expression*, n (\%) & Moderate & $9(43.0)$ \\
& Normal & $4(19.0)$ \\
Deficiency, n (\%) & Intense & $2(9.4)$ \\
Antibody-positive, n (\%) & Iron (anemia) & $19(90.6)$ \\
& Vitamin B12 & $4(19.0)$ \\
& Parietal cell & $6(28.6)$ \\
& Intrinsic factor & $1(4.7)$ \\
& Thyroid peroxidase & $8(38.0)$ \\
\hline
\end{tabular}

AG Atrophic gastritis; AGA: atrophic gastritis of the antrum; AGC: atrophic gastritis of the corpus; AGP: atrophic gastritis of both antrum and corpus; ECL: enterochromaffin-like cell; IM: intestinal metaplasia; USS. Updated Sydney System for classification of gastritis. *Immunohistochemical staining of gastric biopsies.

protracted course of the disease spanning over decades (5961), and ii) recent evidence implied that $H$. pylori can be a trigger of the autoimmune process leading to AAG, i.e., be involved in pathogenesis of AAG (62-65). Several prospective follow-up studies have confirmed that in chronic AG (both AGA and AGC), H. pylori itself can disappear from an atrophic mucosa, and in the absence of antigen stimulus, a normal decay of the $\mathrm{IgG}$ antibody molecules will gradually lead to $H$. pylori antibody levels below the 30 EIU cut-off (59-61). Thus, finding AGC/AGP with no evidence of $H$. pylori infection in the GastroPanel ${ }^{\circledR}$ test can denote two things: i) $H$. pylori-related AGC/AGP, where the pathogenic bacteria have disappeared, or ii) true AAG, with H. pylori never having been involved in the disease process.

As to the later point, the classical pathogenetic mechanism of AAG is well established. The target autoantigens in AAG are the $100-\mathrm{kDa}$ catalytic $\alpha$-subunit, and the $60-$ to $90-\mathrm{kDa}$ glycoprotein $\beta$-subunit of gastric $\mathrm{H}^{+} / \mathrm{K}^{+}$ATPase $(66,67)$. PCA and IFA are present in the serum and in gastric juice. 
Table IV. Case profiles of the 21 subjects who participated in the second round of the study.

\begin{tabular}{|c|c|c|c|c|c|c|c|c|c|c|c|c|c|}
\hline $\begin{array}{l}\text { ID (gender; } \\
\text { age in } \\
\text { years) }\end{array}$ & $\begin{array}{c}\mathrm{Fe} \\
(9-30.4 \\
\mu \mathrm{mol} / \mathrm{l})\end{array}$ & $\begin{array}{c}\text { Ferritin } \\
(10-120 \\
\mu g / 1)\end{array}$ & $\begin{array}{c}\text { Total B12 } \\
(127-883 \\
\text { pmol/l) }\end{array}$ & $\begin{array}{c}\text { Holo-TC } \\
(21-123 \\
\mathrm{pmol} / \mathrm{l})\end{array}$ & $\begin{array}{l}\text { PCA } \\
(<1: 40)\end{array}$ & $\begin{array}{c}\text { IFA } \\
(1.21-1.52 \\
\text { AU/ml })\end{array}$ & $\begin{array}{c}\text { TPA } \\
(<5.6 \\
\text { IU/ml })\end{array}$ & $\begin{array}{c}\text { OLGA } \\
\text { Stage }\end{array}$ & $\begin{array}{c}\text { USS } \\
\text { Grade }\end{array}$ & $\begin{array}{l}\text { ECL } \\
\text { hyp/ } \\
\text { Chr }\end{array}$ & $\begin{array}{c}\text { ELISA } \\
\text { HpA } \\
(<30 \text { EIU })\end{array}$ & $\begin{array}{c}\text { Gastrin-17 } \\
(1-7) \\
\text { pmol/1 }\end{array}$ & $\begin{array}{c}\text { Final } \\
\text { diagnosis }\end{array}$ \\
\hline $1(\mathrm{~F} ; 43)$ & 8.77 & 30 & 272.00 & 26.15 & - & - & $1,000.0$ & 3 & AGC & $2 / 3$ & 9.2 & 40.00 & AAG \\
\hline $2(\mathrm{M} ; 62)$ & - & - & - & - & - & - & - & 2 & AGC & $0 / 3$ & 8.2 & 5.50 & AAG \\
\hline $3(\mathrm{M} ; 33)$ & 14.14 & 18 & 526.00 & 35.52 & $<1: 40$ & 1.70 & 46.3 & 3 & AGC & $2 / 3$ & 32.9 & 40.00 & AAG \\
\hline $4(\mathrm{~F} ; 53)$ & 29.84 & 177 & 232.00 & 35.82 & - & - & 88.7 & 3 & AGC & $2 / 3$ & 3.5 & 40.00 & AAG \\
\hline $5(\mathrm{~F} ; 46)$ & 20.01 & 100 & 359.00 & 44.61 & - & - & 3.0 & 0 & $\mathrm{~N}$ & $0 / 0$ & 45.2 & 40.00 & $\mathrm{~N}$ \\
\hline $6(\mathrm{~F} ; 56)$ & 10.48 & 16 & 21.50 & 15.77 & - & - & 144.6 & 3 & AGC & $3 / 3$ & 14.8 & 40.00 & AAG \\
\hline $7(\mathrm{~F} ; 42)$ & 6.80 & 1.0 & 285.00 & 25.09 & - & - & 3.0 & 2 & AGC & $2 / 3$ & 27.5 & 40.00 & AAG \\
\hline $8(\mathrm{~F} ; 62)$ & 12.33 & 44 & 294.00 & 72.87 & - & - & 3.6 & 1 & AGC & $1 / 3$ & 38.7 & 1.20 & AGC \\
\hline $9(\mathrm{~F} ; 69)$ & 29.22 & 60 & 126.00 & 33.85 & $<1: 40$ & 0.70 & 836.0 & 3 & AGC & $2 / 3$ & 14.9 & 24.10 & AAG \\
\hline $10(\mathrm{~F} ; 48)$ & 11.88 & 11 & 398.00 & 63.69 & $1: 1,280$ & 1.00 & 3.0 & 2 & AGC & $2 / 3$ & 79.9 & 40.00 & AAG \\
\hline $11(\mathrm{~F} ; 38)$ & 4.72 & 3 & 4.43 & - & $<1: 40$ & 1.10 & 394.8 & 1 & AGA & $0 / 3$ & 17.3 & 2.90 & AAG \\
\hline $12(\mathrm{~F} ; 40)$ & 13.63 & 33 & 162.00 & 21.19 & $1: 320$ & 0.90 & 3.0 & 3 & AGC & $2 / 3$ & 7.0 & 40.00 & AAG \\
\hline $13(\mathrm{M} ; 51)$ & 12.22 & 74 & 379.00 & 86.73 & $<1: 40$ & 0.70 & 3.0 & 1 & AGC & $0 / 0$ & 112.1 & 40.00 & AGC \\
\hline $14(\mathrm{M} ; 53)$ & 24.92 & 49 & 246.00 & 45.42 & $<1: 40$ & 0.70 & 3.0 & 2 & AGC & $1 / 3$ & 112.1 & 40.00 & AGC \\
\hline $15(\mathrm{~F} ; 69)$ & 14.89 & 15 & 136.00 & 17.81 & $1: 1,280$ & 1.00 & $1,000.0$ & 3 & AGC & $2 / 3$ & 12.5 & 6.18 & AAG \\
\hline $16(\mathrm{~F} ; 62)$ & 26.32 & 60 & 125.00 & 27.46 & $<1: 40$ & 0.90 & 3.0 & 2 & AGC & $3 / 3$ & 19.9 & 40.00 & AAG \\
\hline $17(\mathrm{M} ; 25)$ & 5.30 & 6 & 329.00 & 77.05 & $<1: 40$ & 1.40 & 3.0 & 2 & AGC & $1 / 3$ & 91.3 & 40.00 & AGC \\
\hline $18(\mathrm{~F} ; 65)$ & 20.48 & 20 & 153.00 & 20.80 & - & - & 61.5 & 3 & AGC & $2 / 3$ & 102.2 & 32.90 & AAG \\
\hline $19(\mathrm{M} ; 37)$ & 19.98 & 49 & 279.00 & 64.62 & $1: 2,560$ & 1.10 & 3.0 & 3 & AGC & $3 / 3$ & 7.1 & 40.00 & AAG \\
\hline $20(\mathrm{~F} ; 38)$ & 10.91 & 21 & 278.00 & - & $1: 5,120$ & 1.00 & 3.2 & 2 & AGC & $3 / 3$ & 93.0 & 40.00 & AAG \\
\hline $21(\mathrm{~F} ; 76)$ & - & - & - & - & - & - & - & 3 & AGP & $1 / 3$ & 156.1 & 8.30 & AGP \\
\hline
\end{tabular}

AAG: Autoimmune atrophic gastritis; AGC: Atrophic gastritis of the corpus; AGP: atrophic gastritis of both antrum and corpus; N, normal mucosa; ECL hyp: enterochromaffin-like cell hyperplasia; Fe: serum iron; G-17: gastrin-17; Holo-TC: holotranscobalamine (active vitamin B12); HpA: Helicobacter pylori IgG antibody; IFA: intrinsic factor antibody; OLGA: operative link to gastric atrophy; PCA: parietal cell antibody; Total B12: total vitamin B12; TPO Ab: thyroid peroxidase antibody; USS: Updated Sydney System. All abnormal test results are shown in bold. Reference values for parameters are shown in parentheses.

The titer of PCA is closely correlated with the severity of AGC and is inversely proportional to the density of PCs. During normal cell turnover, PCs release $\mathrm{H}^{+} / \mathrm{K}^{+}$ATPase, which may result in its selective uptake and processing by antigen-presenting cells (68). It is the $\mathrm{CD}^{+}{ }^{+} \mathrm{T}$-cells that recognize $\mathrm{PC} \mathrm{H}^{+} / \mathrm{K}^{+}$ATPase and facilitate AAG (64-68).

Alternatively, $H$. pylori infection may play an initiating role in the pathogenesis of AAG (62-65) by inducing autoreactive T-cells through gastric $\mathrm{H}^{+} / \mathrm{K}^{+}$ATPase $-H$. pylori molecular mimicry at the T-cell level $(64,65)$. B-Cells produce autoantibodies to gastric $\mathrm{H}^{+} / \mathrm{K}^{+}$ATPase and to their secretory product, IF, with help from activated $\mathrm{CD} 4^{+} \mathrm{T}$-cells (67). Finally, PC loss from the gastric mucosa may result from $\mathrm{CD} 4^{+}$T-cell-initiated perforin-mediated cytotoxicity or Fas-FasL-induced apoptosis (65). Although the role of $H$. pylori as a trigger of AAG still needs additional confirmation (17), the role of this bacterium in the pathogenesis of AAG cannot be ruled out (62-68). The H. pylori -status in the GastroPanel ${ }^{\circledR}$ test is therefore not a reliable indicator for confirming or excluding the diagnosis of AAG. Of note, of the 15 confirmed AAG cases in the present cohort, four tested positive for $H$. pylori in the GastroPanel ${ }^{\circledR}$ test.
Thus, if in the present study, all AGC/AGP cases that remained $H$. pylori-negative in the GastroPanel ${ }^{\circledR}$ test had been defined as AAG without applying any of the other diagnostic tests for AAG, one would end up with a markedly biased underestimate of the AAG prevalence. Accordingly, of the 1,283 tested subjects, AGC and AGP comprised 46 cases (Table I). Of those 46 cases, 31 were classified as $H$. pylori-positive (using the 30 EIU cut-off), while 15 were $H$. pylori-negative. This would translate to an AAG prevalence of 15/1,283 (1.2\%) (data not shown). The truth, however, is that of the 46 AG-positive subjects, 25 missed the invitation or refused further examinations, i.e., were non-attenders in the second study round, causing substantial verification bias (i.e., subjects with no confirmatory tests applied).

To estimate the true prevalence of AAG in the present cohort necessitates that the established numbers (15 AAG cases out of 21 subjects with complete verification) must be corrected for this verification bias. When this is done, by assuming that the same proportion of AGC/AGP cases in reality represent $\mathrm{AAG}$ among i) the 21 cases with full verification and ii) the 25 non-attendees, the true 
prevalence of AAG would be $2.6 \%(33 / 1,283)$ for this cohort. As compared with the figures reported in the world literature, with AAG prevalence in the general population ranging between $0.1 \%$ and $1-2 \%$ (1-9), the prevalence in the present cohort is among the highest ever reported for asymptomatic, population-based cohorts. AAG prevalence rates of a similar scale (0.3-2.7\%) have been reported only in studies where esophagogastroduodenoscopy was used as the screening tool for AAG $(1,3,30,32)$. This is a clear indication to support the use of the present strategy, where asymptomatic subjects are first screened by a non-invasive biomarker test (GastroPanel ${ }^{\circledR}$ ) to reveal those potentially affected by AAG (i.e. all cases with on AGC/AGP biomarker profile), who should be further analyzed by gastroscopy and biopsies, as well as by the laboratory tests for AAG-specific biomarkers (PCA and IFA), AAG-related co-morbidities (iron deficiency and PA)(30-33), and other related autoimmune conditions (TPA) frequently accompanying AAG (1, 3, 20-24).

In the present series, a carefully selected panel of tests (in addition to gastroscopy) was used to confirm or exclude the presence of AAG among those who were diagnosed with AGC/AGP in the initial GastroPanel ${ }^{\circledR}$ screening (Table IV). As anticipated from recent studies (46-48), there was an extremely close correlation between the GastroPanel ${ }^{\circledR}$ results and gastroscopic examination, all AGC/AGP cases being confirmed by the macroscopic observations in gastroscopy. The same was true for the gastroscopic biopsies, except for one case where the biopsy did not find atrophy diagnosed in the GastroPanel ${ }^{\circledR}$ test and confirmed in gastroscopy (case 5, Table IV). The only feasible reason to explain this obvious discrepancy is the failure to correctly target the biopsy at the site of atrophy. As to the detection of high-titer PCA and IFA, these were present in 5/21 and $1 / 21$ subjects. These results are in alignment with studies that examined PCA and IFA in different settings of patients with AA to the $(21-24,28,29)$. Similar to the disappearance of Helicobacter in end-stage AGC (59-61), PCA and IFA can also disappear (or undergo decay) when their autoantigen targets (PCs) disappear in the severely atrophic mucosa. Indeed, this was the situation in the majority of the present cases, who represented advanced OLGA stages of gastric atrophy (Table IV).

In this series, the tests measuring AAG-associated comorbidities as well as the coexistent autoimmune disorders proved to be highly informative. Altogether, 10 out of 21 patients were diagnosed with iron deficiency or PA, and in eight of these patients, evidence for AITD was provided by high-titer TPA. Given that all these 1,283 individuals represented otherwise healthy, asymptomatic adults, this whole cohort is an outstanding example of this disease; in the vast majority of cases, AAG is asymptomatic and diagnosed as an incidental finding among patients examined for other conditions, such as iron-deficiency anemia, PA or other autoimmune conditions (36). The present study also underlines the important role of serological biomarker screening by GastroPanel ${ }^{\circledR}$, as this non-invasive diagnostic tool provides first-line evidence for potential AAG; having revealed the characteristic biomarker profile of AGC/AGP, the final diagnosis of $\mathrm{AAG}$ can easily be reached using specific laboratory tests.

\section{Conclusion}

According to the present screening of asymptomatic healthy adults by the non-invasive serological biomarker assay GastroPanel ${ }^{\circledR}$, the unadjusted prevalence of AAG in the Russian Federation is $1.2 \%(15 / 1,283)$, representing a higher than average rate in the global statistics. Because of the verification bias due to 25 non-attendees for the reference test, the adjusted prevalence of AAG was $2.6 \%$ $(33 / 1,283)$, which is among the highest reported figures globally, usually found in studies using endoscopic screening. Given that in the vast majority of cases, this condition is discovered as an incidental finding, this study confirms that a non-invasive serological biomarker test (GastroPanel ${ }^{\circledR}$ ) is an optimal screening tool in the diagnostic protocol that leads to the final diagnosis of AG. On the basis of the present discovery of $H$. pylori in almost $30 \%$ of AAG cases, one cannot rule out the role of this bacterium as a trigger of AAG.

\section{Conflicts of Interest}

None declared.

\section{Authors' Contributions}

All Authors have met all the following four criteria: i) Substantial contributions to the conception or design of the work or the acquisition, analysis, or interpretation of data for the work. ii) Drafting of the work or revising it critically for important intellectual content. iii) Final approval of the version to be published. iv) Agreement to be accountable for all aspects of the work in ensuring that questions related to the accuracy or integrity of any part of the work are appropriately investigated and resolved.

\section{Acknowledgements}

This study was performed in co-operation with OMEGA Farma and MELON (St. Petersburg, Russian Federation) and Biohit Oyj (Helsinki, Finland). The skillful technical assistance of the following persons is gratefully acknowledged for their important input in the different phases of the study: Mr. Igor Stadnik, Ms Maria Antonova, Mrs. Anita Mikkola, Mrs. Kaisa Friberg, Ms. Milla Mikkola, Mrs. Pia Rinkinen, Dr. Tapani Tiusanen, PhD, Dr. Minna Mäki, PhD, Suvi Elomaa, B.Sc. and Mrs. Heli Holopainen. 


\section{References}

1 Rustgi SD, Bijlani P and Shah SC: Autoimmune gastritis, with or without pernicious anemia: epidemiology, risk factors, and clinical management. Therap Adv Gastroenterol 14: 17562848211038771, 2021. PMID: 34484423. DOI: 10.1177/17562848211038771

2 Miceli E, Lenti MV, Padula D, Luinetti O, Vattiato C, Monti CM, Di Stefano M and Corazza GR: Common features of patients with autoimmune atrophic gastritis. Clin Gastroenterol Hepatol 10(7): 812-814, 2012. PMID: 22387252. DOI: $10.1016 / \mathrm{j} . \operatorname{cgh} .2012 .02 .018$

3 Kulnigg-Dabsch S: Autoimmune gastritis. Wien Med Wochenschr 166(13-14): 424-430, 2016. PMID: 27671008. DOI: 10.1007/s10354-016-0515-5

4 Centanni M, Marignani M, Gargano L, Corleto VD, Casini A, Delle Fave G, Andreoli M and Annibale B: Atrophic body gastritis in patients with autoimmune thyroid disease: an underdiagnosed association. Arch Intern Med 159(15): 1726-1730, 1999. PMID: 10448775. DOI: 10.1001/archinte.159.15.1726

5 Strickland RG and Mackay IR: A reappraisal of the nature and significance of chronic atrophic gastritis. Am J Dig Dis 18(5): 426-440, 1973. PMID: 4573514. DOI: 10.1007/BF01071995

6 Whittingham S and Mackay IR: Pernicious anemia and gastric atrophy. In: Rose NR and Mackay IR: eds. The Autoimmune Diseases. New York, Academic Press, pp. 243-266, 1985.

7 Jacobson DL, Gange SJ, Rose NR and Graham NM: Epidemiology and estimated population burden of selected autoimmune diseases in the United States. Clin Immunol Immunopathol 84(3): 223-243, 1997. PMID: 9281381. DOI: 10.1006/clin.1997.4412

8 Annibale B, Esposito G and Lahner E: A current clinical overview of atrophic gastritis. Expert Rev Gastroenterol Hepatol 14(2): 93102, 2020. PMID: 31951768. DOI: 10.1080/17474124.020.1718491

9 Lahner E, Conti L, Annibale B and Corleto VD: Current perspectives in atrophic gastritis. Curr Gastroenterol Rep 22(8): 38, 2020. PMID: 32542467. DOI: 10.1007/s11894-020-00775-1

10 Mäkimattila S, Harjutsalo V, Forsblom C, Groop PH and FinnDiane Study Group: Every fifth individual with type 1 diabetes suffers from an additional autoimmune disease: a Finnish nationwide study. Diabetes Care 43(5): 1041-1047, 2020. PMID: 32139386. DOI: $10.2337 / \mathrm{dc} 19-2429$

11 Maclaren NK and Riley WJ: Thyroid, gastric, and adrenal autoimmunities associated with insulin-dependent diabetes mellitus. Diabetes Care 8(Suppl 1): 34-38, 1985. PMID: 4053951. DOI: $10.2337 /$ diacare.8.1.s34

12 Betterle C, Zanette F, Pedini B, Presotto F, Rapp LB, Monciotti $\mathrm{CM}$ and Rigon F: Clinical and subclinical organ-specific autoimmune manifestations in type 1 (insulin-dependent) diabetic patients and their first-degree relatives. Diabetologia 26(6): 431436, 1984. PMID: 6381190. DOI: 10.1007/BF00262215

13 Landin-Olsson M, Karlsson FA, Lernmark A and Sundkvist G: Islet cell and thyrogastric antibodies in 633 consecutive 15- to 34-yr-old patients in the diabetes incidence study in Sweden. Diabetes 41(8): 1022-1027, 1992. PMID: 1628762. DOI: 10.2337/diab.41.8.1022

14 Carmel R: Prevalence of undiagnosed pernicious anemia in the elderly. Arch Intern Med 156(10): 1097-1100, 1996. PMID: 8638997.

15 Betterle C, Mazzi PA, Pedini B, Accordi F, Cecchetto A and Presotto F: Complement-fixing gastric parietal cell autoantibodies.
A good marker for the identification of type A chronic atrophic gastritis. Autoimmunity 1(4): 267-274, 1988. PMID: 2979621. DOI: $10.3109 / 08916938809010680$

16 Oksanen A, Sipponen P, Karttunen R, Miettinen A, Veijola L, Sarna S and Rautelin H: Atrophic gastritis and Helicobacter pylori infection in outpatients referred for gastroscopy. Gut 46(4): 460463, 2000. PMID: 10716672. DOI: 10.1136/gut.46.4.460

17 De Block CE, De Leeuw IH and Van Gaal LF: Autoimmune gastritis in type 1 diabetes: a clinically oriented review. J Clin Endocrinol Metab 93(2): 363-371, 2008. PMID: 18029461. DOI: $10.1210 /$ jc. $2007-2134$

18 Ungar B, Stocks AE, Martin FI, Whittingham S and Mackay IR: Intrinsic-factor antibody, parietal-cell antibody, and latent pernicious anaemia in diabetes mellitus. Lancet 2(7565): 415-417, 1968. PMID: 4174152. DOI: 10.1016/s0140-6736(68)90462-5

19 De Block CE, De Leeuw IH, Vertommen JJ, Rooman RP, Du Caju MV, Van Campenhout CM, Weyler JJ, Winnock F, Van Autreve J, Gorus FK and Belgian Diabetes Registry: Beta-cell, thyroid, gastric, adrenal and coeliac autoimmunity and HLA-DQ types in type 1 diabetes. Clin Exp Immunol 126(2): 236-241, 2001. PMID: 11703366. DOI: 10.1046/j.1365-2249.2001.01668.x

20 Tozzoli R, Kodermaz G, Perosa AR, Tampoia M, Zucano A, Antico A and Bizzaro N: Autoantibodies to parietal cells as predictors of atrophic body gastritis: a five-year prospective study in patients with autoimmune thyroid diseases. Autoimmun Rev 10(2): 80-83, 2010. PMID: 20696284. DOI: 10.1016/j.autrev.2010.08.006

21 Venerito M, Radünz M, Reschke K, Reinhold D, Frauenschläger K, Jechorek D, Di Mario F and Malfertheiner P: Autoimmune gastritis in autoimmune thyroid disease. Aliment Pharmacol Ther 41(7): 686-693, 2015. PMID: 25648057. DOI: 10.1111/apt.13097

22 Castoro C, Le Moli R, Arpi ML, Tavarelli M, Sapuppo G, Frittitta L, Squatrito $S$ and Pellegriti G: Association of autoimmune thyroid diseases, chronic atrophic gastritis and gastric carcinoid: experience from a single institution. J Endocrinol Invest 39(7): 779-784, 2016. PMID: 26928404. DOI: 10.1007/s40618-016-0445-5

23 Lahner E, Centanni M, Agnello G, Gargano L, Vannella L, Iannoni C, Delle Fave G and Annibale B: Occurrence and risk factors for autoimmune thyroid disease in patients with atrophic body gastritis. Am J Med 121(2): 136-141, 2008. PMID: 18261502. DOI: 10.1016/j.amjmed.2007.09.025

24 d'Annunzio G, Russo C, Tallone R and Lorini R: Autoimmune disorders associated to type 1 diabetes mellitus in children and adolescents, Chapter 1. In: Autoimmune Disorders - Current Concepts and Advances from Bedside to Mechanistic Insights. Fang-Ping Huang (ed.). Intech Open, pp. 1-26, 2011. Available at: https://www.intechopen.com/chapters/20659 [Last accessed on January 20, 2022]

25 De Block CE, Van Campenhout CM, De Leeuw IH, Keenoy BM, Martin M, Van Hoof V and Van Gaal LF: Soluble transferrin receptor level: a new marker of iron deficiency anemia, a common manifestation of gastric autoimmunity in type 1 diabetes. Diabetes Care 23(9): 1384-1388, 2000. PMID: 10977038. DOI: $10.2337 /$ diacare.23.9.1384

26 Annibale B, Capurso G and Delle Fave G: The stomach and iron deficiency anaemia: a forgotten link. Dig Liver Dis 35(4): 288-295, 2003. PMID: 12801042. DOI: 10.1016/s1590-8658(03)00067-7

27 Toh BH and Alderuccio F: Pernicious anaemia. Autoimmunity 37(4): 357-361, 2004. PMID: 15518059. DOI: 10.1080/089169 30410001705439 
28 Irvine WJ, Cullen DR and Mawhinney H: Natural history of autoimmune achlorhydric atrophic gastritis. A 1-15-year followup study. Lancet 2(7879): 482-485, 1974. PMID: 4137076. DOI: 10.1016/s0140-6736(74)92013-3

29 Kokkola A, Sjöblom SM, Haapiainen R, Sipponen P, Puolakkainen $\mathrm{P}$ and Järvinen $\mathrm{H}$ : The risk of gastric carcinoma and carcinoid tumours in patients with pernicious anaemia. A prospective follow-up study. Scand J Gastroenterol 33(1): 88-92, 1998. PMID: 9489914. DOI: $10.1080 / 00365529850166266$

30 Armbrecht U, Stockbrügger RW, Rode J, Menon GG and Cotton PB: Development of gastric dysplasia in pernicious anaemia: a clinical and endoscopic follow up study of 80 patients. Gut 31(10): 1105-1109, 1990. PMID: 2083855. DOI: 10.1136/gut.31.10.1105

31 Borch K, Renvall H and Liedberg G: Gastric endocrine cell hyperplasia and carcinoid tumors in pernicious anemia. Gastroenterology 88(3): 638-648, 1985. PMID: 2578420. DOI: 10.1016/0016-5085(85)90131-3

32 Sjöblom SM, Sipponen P and Järvinen H: Gastroscopic follow up of pernicious anaemia patients. Gut 34(1): 28-32, 1993. PMID: 8432447. DOI: 10.1136/gut.34.1.28

33 Hsing AW, Hansson LE, McLaughlin JK, Nyren O, Blot WJ, Ekbom A and Fraumeni JF Jr: Pernicious anemia and subsequent cancer. A population-based cohort study. Cancer 71(3): 745-750, 1993. PMID: 8431855. DOI: 10.1002/1097-0142(19930201) 71:3<745::aid-cncr2820710316>3.0.co;2-1

34 Brinton LA, Gridley G, Hrubec Z, Hoover R and Fraumeni JF Jr: Cancer risk following pernicious anaemia. Br J Cancer 59(5): 810-813, 1989. PMID: 2736218. DOI: 10.1038/bjc.1989.169

35 Case records of the Massachusetts General Hospital. Weekly clinicopathological exercises. Case 40-2000. A 38-year-old woman with gastric adenocarcinoma. N Engl J Med 343(26): 1951-1958, 2000. PMID: 11136267. DOI: 10.1056/NEJM200012283432608

36 Rugge M, Genta RM, Bricca L and Savarino E: Not all autoimmune gastritis are created the same. Gastroenterology Res 14(6): 348-349, 2021. PMID: 35059069. DOI: 10.14740/gr1443

37 Kato M: Endoscopic features of early-stage autoimmune gastritis. Intern Med 59(23): 2969-2970, 2020. PMID: 32759598. DOI: 10.2169/internalmedicine.5603-20

38 Toh BH, van Driel IR and Gleeson PA: Pernicious anemia. N Engl J Med 337(20): 1441-1448, 1997. PMID: 9358143. DOI: 10.1056/NEJM199711133372007

39 Antico A, Tampoia M, Villalta D, Tonutti E, Tozzoli R and Bizzaro N: Clinical usefulness of the serological gastric biopsy for the diagnosis of chronic autoimmune gastritis. Clin Dev Immunol 2012: 520970， 2012. PMID: 23251219. DOI: $10.1155 / 2012 / 520970$

40 Oksanen A, Sipponen P, Miettinen A, Sarna S and Rautelin H: Evaluation of blood tests to predict normal gastric mucosa. Scand J Gastroenterol 35(8): 791-795, 2000. PMID: 10994615. DOI: $10.1080 / 003655200750023138$

41 Varis K, Sipponen P, Laxén F, Samloff IM, Huttunen JK, Taylor PR, Heinonen OP, Albanes D, Sande N, Virtamo J and Härkönen M: Implications of serum pepsinogen I in early endoscopic diagnosis of gastric cancer and dysplasia. Helsinki Gastritis Study Group. Scand J Gastroenterol 35(9): 950-956, 2000. PMID: 11063155. DOI: 10.1080/003655200750023011

42 Agréus L, Kuipers EJ, Kupcinskas L, Malfertheiner P, Di Mario F, Leja M, Mahachai V, Yaron N, van Oijen M, Perez Perez G, Rugge M, Ronkainen J, Salaspuro M, Sipponen P, Sugano K and Sung J: Rationale in diagnosis and screening of atrophic gastritis with stomach-specific plasma biomarkers. Scand J Gastroenterol 47(2): 136-147, 2012. PMID: 22242613. DOI: $10.3109 / 00365521.2011 .645501$

43 GastroPanel. Available at: https://www.gastropanel.com/ [Last accessed on August 20, 2021]

44 Benberin V, Bektayeva R, Karabayeva R, Lebedev A, Akemeyeva K, Paloheimo L and Syrjänen K: Prevalence of $H$. pylori infection and atrophic gastritis among symptomatic and dyspeptic adults in Kazakhstan. A hospital-based screening study using a panel of serum biomarkers. Anticancer Res 33(10): 4595-4602, 2013. PMID: 24123036.

45 Roman LD, Lukyanchuk R, Sablin OA, Araslanova EI, Eklund C, Hendolin P, Paloheimo L and Syrjänen K: Prevalence of $H$. pylori infection and atrophic gastritis in a population-based screening with serum biomarker panel (GastroPane ${ }^{\circledR}$ ) in St. Petersburg. Anticancer Res 36(8): 4129-4138, 2016. PMID: 27466521.

46 Koivurova O-P, Ukkola O, Koivikko M, Ebeling T, Yliaska I, Koskela R, Blomster T, Ala-Rämi A, Kettunen OP, Karttunen TJ, Mäkinen M, Ronkainen $\mathrm{J}$ and Syrjänen K: Screening of the patients with autoimmune thyroid disease (AITD) and type 1 diabetes mellitus (DM1) for atrophic gastritis (AG) by serological biomarker testing (GastroPanel ${ }^{\circledR}$ ). EC Gastroenterol Digest Syst 7(9): 181-195, 2020.

47 MÄki M, SÖderstrÖm D, Paloheimo L, Hendolin P, Suovaniemi O and SyrjÄnen K: Helicobacter pylori (Hp) IgG ELISA of the newgeneration GastroPanel ${ }^{\circledR}$ is highly accurate in diagnosis of Hpinfection in gastroscopy referral patients. Anticancer Res 40(11): 6387-6398, 2020. PMID: 33109577. DOI: 10.21873/anticanres. 14660

48 Koivurova OP, Koskela R, Blomster T, Ala-Rämi A, Lumme H, Kettunen O, Hukkanen J, Karttunen TJ, Mäkinen M, Ronkainen $\mathrm{J}$ and Syrjänen K: Serological biomarker panel in diagnosis of atrophic gastritis and Helicobacter pylori infection in gastroscopy referral patients: Clinical validation of the newgeneration GastroPanel ${ }^{\circledR}$ test. Anticancer Res 41(11): 5527-5537, 2021. PMID: 34732423. DOI: 10.21873/anticanres.15366

49 Syrjänen K: A panel of serum biomarkers (GastroPanel ${ }^{\circledR}$ ) in non-invasive diagnosis of atrophic gastritis. Systematic review and meta-analysis. Anticancer Res 36(10): 5133-5144, 2016. PMID: 27798873. DOI: 10.21873/anticanres.11083

50 Zagari RM, Rabitti S, Greenwood DC, Eusebi LH, Vestito A and Bazzoli F: Systematic review with meta-analysis: diagnostic performance of the combination of pepsinogen, gastrin-17 and anti-Helicobacter pylori antibodies serum assays for the diagnosis of atrophic gastritis. Aliment Pharmacol Ther 46(7): 657-667, 2017. PMID: 28782119. DOI: 10.1111/apt.14248

51 Syrjänen KJ, Sipponen P, Härkönen M, Peetsalu A and Korpela S: Accuracy of the GastroPanel test in the detection of atrophic gastritis. Eur J Gastroenterol Hepatol 27(1): 102-104, 2015. PMID: 25426982. DOI: 10.1097/MEG.0000000000000215

52 Dixon MF, Genta RM, Yardley JH and Correa P: Classification and grading of gastritis. The updated Sydney System. International Workshop on the Histopathology of Gastritis, Houston 1994. Am J Surg Pathol 20(10): 1161-1181, 1996. PMID: 8827022. DOI: 10.1097/00000478-199610000-00001

53 Rugge M, Genta RM, Fassan M, Valentini E, Coati I, Guzzinati S, Savarino E, Zorzi M, Farinati $F$ and Malfertheiner P: OLGA gastritis staging for the prediction of gastric cancer risk: a longterm follow-up study of 7436 patients. Am J Gastroenterol 113(11): 1621-1628, 2018. PMID: 30333540. DOI: 10.1038/s41395-018$0353-8$ 
54 BIOHIT Active B12 (Holotranscobalamin). Instructions for Use. Available at: https://www.biohithealthcare.com/wp-content/ uploads/2019/01/400920-02-biohit-active-b12-ifu-eng-final.pdf [Last accessed on January 28, 2022]

55 Alekberzade AV, Krylov NN, Lipnitskiy EM, Shakhbazov RO and Azari F: [Gastric neuroendocrine tumors]. Khirurgiia (Mosk) (12): 111-120, 2019. PMID: 31825351. DOI: 10.17116/hirurgia2019121111

56 Belkovets A V, Kurilovich SA, Reshetnikov OV, Ragino YI and Scherbakova LV: Prevalence and peculiarity of corpus atrophic gastritis in population with high level of Helicobacter pylori infection. Eksp Klin Gastroenterol (9): 8-13, 2016. PMID: 29889388

57 Syrjänen K, Eskelinen M, Peetsalu A, Sillakivi T, Sipponen P, Härkönen M, Paloheimo L, Mäki M, Tiusanen T, Suovaniemi O, DiMario F and Fan ZP: GastroPanel ${ }^{\circledR}$ biomarker assay: The most comprehensive test for Helicobacter pylori infection and its clinical sequelae. A critical review. Anticancer Res 39(3): 10911104, 2019. PMID: 30842138. DOI: 10.21873/anticanres.13218

58 Sipponen P, Sarna S and Vohlonen I: When will Helicobacter pylori gastritis disappear in history in Finland? Scand J Gastroenterol 57(2): 154-157, 2022. PMID: 34757871. DOI: 10.1080/00365521.2021.1998605

59 Kokkola A, Rautelin H, Puolakkainen P, Sipponen P, Färkkilä M, Haapiainen R and Kosunen TU: Positive result by serology indicates active Helicobacter pylori infection in patients with atrophic gastritis. J Clin Microbiol 36(6): 1808-1810, 1998. PMID: 9620430. DOI: 10.1128/JCM.36.6.1808-1810.1998

60 Kokkola A, Rautelin H, Puolakkainen P, Sipponen P, Färkkilä M, Haapiainen R and Kosunen TU: Diagnosis of Helicobacter pylori infection in patients with atrophic gastritis: comparison of histology, 13C-urea breath test, and serology. Scand J Gastroenterol 35(2): 138-141, 2000. PMID: 10720110. DOI: $10.1080 / 003655200750024290$

61 Kokkola A, Kosunen TU, Puolakkainen P, Sipponen P, Harkonen M, Laxen F, Virtamo J, Haapiainen $\mathrm{R}$ and Rautelin $\mathrm{H}$ : Spontaneous disappearance of Helicobacter pylori antibodies in patients with advanced atrophic corpus gastritis. APMIS 111(6): 619-624, 2003. PMID: 12969017. DOI: 10.1034/j.16000463.2003.1110604.X
62 Appelmelk BJ, Faller G, Claeys D, Kirchner $\mathrm{T}$ and Vandenbroucke-Grauls CM: Bugs on trial: the case of Helicobacter pylori and autoimmunity. Immunol Today 19(7): 296-299, 1998. PMID: 9666600. DOI: 10.1016/s0167-5699(98)01281-x

63 Amedei A, Bergman MP, Appelmelk BJ, Azzurri A, Benagiano M, Tamburini C, van der Zee R, Telford JL, Vandenbroucke-Grauls CM, D'Elios MM and Del Prete G: Molecular mimicry between Helicobacter pylori antigens and $\mathrm{H}^{+}, \mathrm{K}^{+}$-adenosine triphosphatase in human gastric autoimmunity. J Exp Med 198(8): 1147-1156, 2003. PMID: 14568977. DOI: 10.1084/jem.20030530

64 van Driel IR, Read S, Zwar TD and Gleeson PA: Shaping the T cell repertoire to a bona fide autoantigen: lessons from autoimmune gastritis. Curr Opin Immunol 17(6): 570-576, 2005. PMID: 16214318. DOI: 10.1016/j.coi.2005.09.016

65 D'Elios MM, Appelmelk BJ, Amedei A, Bergman MP and Del Prete G: Gastric autoimmunity: the role of Helicobacter pylori and molecular mimicry. Trends Mol Med 10(7): 316-323, 2004. PMID: 15242679. DOI: 10.1016/j.molmed.2004.06.001

66 Karlsson FA, Burman P, Lööf L and Mårdh S: Major parietal cell antigen in autoimmune gastritis with pernicious anemia is the acid-producing $\mathrm{H}^{+}, \mathrm{K}^{+}$-adenosine triphosphatase of the stomach. J Clin Invest 81(2): 475-479, 1988. PMID: 2828428. DOI: $10.1172 / \mathrm{JCI} 113344$

67 Toh BH, Sentry JW and Alderuccio F: The causative $\mathrm{H}^{+} / \mathrm{K}^{+}$ ATPase antigen in the pathogenesis of autoimmune gastritis. Immunol Today 21(7): 348-354, 2000. PMID: 10871877. DOI: 10.1016/s0167-5699(00)01653-4

68 van Driel IR, Baxter AG, Laurie KL, Zwar TD, La Gruta NL, Judd LM, Scarff KL, Silveira PA and Gleeson PA: Immunopathogenesis, loss of $\mathrm{T}$ cell tolerance and genetics of autoimmune gastritis. Autoimmun Rev 1(5): 290-297, 2002. PMID: 12848983. DOI: 10.1016/s1568-9972(02)00066-6

Received January 9, 2022

Revised January 25, 2022

Accepted January 28, 2022 